\title{
Taxing Fragmented Aid to Improve Aid Efficiency
}

\author{
September 28, 2018
}

\begin{abstract}
We present a model with multiple donors-principals that provide funds to a unique recipient-agent. Each donor decides how to allocate his aid funds between a pooled and an unilateral project. Both the principals and the agent value the output produced with the pooled funds and the unilateral projects. However donors have a bias in favor of their own unilateral project, which leads them to over-invest in these projects. We propose a tax scheme on the unilateral projects, which acts as a protection measure against biased allocation by the principals. The optimal tax imposed on unilateral projects varies depending on the total amount of aid provided by the donor and on the productivity of his unilateral project. Such a mechanism fits into the current discussion on bilateral negotiations on aid funds tax exemptions.
\end{abstract}

Keywords: Aid fragmentation, taxation, multi-principals, Development JEL codes: D82, D86, F35, O19 


\section{Introduction}

Until recently the literature on aid has focused on recipient countries and macro-economic issues. After several decades of empirical studies, the effectiveness of aid in promoting growth is still very much debated. ${ }^{1}$ Although the macro approach aggregates at the country level the different sources of aid and treats them as a single pool, thanks to the availability of more detailed project-level data, researchers have started to focus on donors behavior and micro-economic issues. These papers have been key to shift the aid effectiveness debate towards the donors' role and their motivations. ${ }^{2}$ Among the different metrics studied at the micro level, fragmentation - both between donors and channels of delivery - has been shown to be a major source of inefficiency. ${ }^{3}$ The goal of this paper is to explore how standard economic tools, such as taxation, can be used to address the aid fragmentation problem and, therefore, to increase aid effectiveness. The idea is simple: since bilateral donors are biased towards their own (uncoordinated) projects with high implementation costs for the recipient, recipients should tax these unilateral projects to correct for the inefficiency.

Proliferation of donors makes the aid business a maze. Alongside the bilateral aid, traditionally provided by OECD-DAC countries but, more recently, also by emerging countries such as China, Brazil or the Arab countries $^{4}$ and the multilateral aid provided by multilateral organizations such as the World Bank or the Regional Development Banks, there are thousands of national and international NGOs, foundations and private entities providing aid. Moreover, not only official development assistance is coming from different countries and organizations, but even at a donor country level it is spread among several agencies. ${ }^{5}$

From the point of view of the recipients, aid fragmentation generates huge transaction costs. ${ }^{6}$ As a result administrative costs absorbed $4.7 \%$ of gross

\footnotetext{
${ }^{1}$ For surveys of this literature see for instance Rajan and Subramanian (2008) and Doucouliagos and Paldam (2009).

${ }^{2}$ See for instance Tingley (2010), Dreher and Kilby (2010), Dreher et al. (2013a) and Dreher et al. (2013b).

${ }^{3}$ See Gehring et al. (2017) for a survey of this literature and discussion in Section 2.

${ }^{4}$ See Walz and Ramachandran (2011) for a review of emerging donors behavior and Dreher et al. (2011) for a comparison of DAC and non-DAC donors.

${ }^{5}$ For instance US foreign assistance programs are fragmented across more than 50 bureaucracies and USAID is overseeing only $45 \%$ of total US foreign aid (Brainard (2007)). Similarly in Germany the ministry for international cooperation coordinates less than 40\% of all German development aid. See http://ipsnews.net/news.asp?idnews $=46043$

${ }^{6}$ For example, the Tanzanian government has to prepare over 2000 reports to donors
} 
bilateral ODA in 2005, which is big compared to the $9.6 \%$ that went to humanitarian and food aid or the $2.2 \%$ that went to NGO's (OECD (2008b)). The donor community acknowledges the 'Donor coordination' problem, but efforts so far to fix it have been deficient. In fact, since the Paris Declaration on Aid Effectiveness, fragmentation of aid has increased instead of diminishing (see Figure 1).

The paper explores how a recipient country (the agent) might use taxation to alleviate the problem of aid fragmentation posed by the donors' uncoordinated competition (the principals). To be more specific, in our setting there are multiple principals that provide funds to a unique agent. Each of the donors can choose the share of his funds that he wants to pool and the share that he wants to use in his unilateral project. ${ }^{7}$ The production function of development depends positively on the inputs (pooled funds and each unilateral project). They are complements in the sense that the development good is only produced if a minimum of each of these inputs is provided. Both the donors and the recipient value the output produced with the principals' (pooled and unilateral) funded projects and this output is non-excludable and non-rival. However the unilateral projects have generally more value to the donors than to the recipient: Each donor gets a private benefit from the funds allocated to his unilateral project. We consider as an illustration the limit case where one of the unilateral projects has no value at all for the recipient. The recipient country might impose a tax on unilateral aid flows. By raising the cost of allocating aid to unilateral projects, relative to pooled aid, the recipient country obliges the donors to internalize the negative externality they create on the development outcome by their uncoordinated and biased behavior.

In the benchmark case there is no vested interest: Donors only care for development outcome, and recipient maximizes development outcome minus administrative costs (i.e., is trading-off macro-economic objectives with

and 1000 delegations every year (Easterly and Birdsall (2008)). The management of donor visits became such a big problem that the country had to declare a 'mission holiday' - a four month period to take a break from visiting delegations (Birdsall (2005)). Each of the donors represents different accountability and procurement rules, and the need to make the project the donors want to fund match with the existing recipient country's portfolio.

${ }^{7}$ We focus on the donor's allocation of funds between unilateral projects and projects coordinated with other donors at the recipient country level. We do not include in our model the donor's choice between multilateral and bilateral aid. The literature on multilateral versus bilateral aid is extensive (see Gulrajani (2016) for a recent survey, and Findley et al. (2017) for discussion on effectiveness of each type of aid) and the discussion on the proliferation of multilateral institutions is active (see Kellerman (2018)), as is the literature on the political influence in these institutions. 
micro-economic constraints). Because of the administrative costs involved in aid management there is a maximum volume of aid that the recipient can handle. Above this threshold the aid is wasted. We find that the way the aid budget is distributed between the donors matters. A necessary condition for the uncoordinated outcome to be efficient (i.e., to be the same as the outcome chosen by a benevolent planner who would pool all the funds) is that the aid budget of each principal is proportional to the relative productivity of his unilateral project. This first result militates against the micro-aid schemes favored by some donor countries. ${ }^{8}$ Such cosmetic aid should be banned as it creates more problems than it solves.

In addition to the inefficiency generated by a suboptimal distribution of budgets among the donors, some donors want to push their own project over the development goal. We show that with biased principals the contributions to unilateral projects are greater than the welfare maximizing level. Intuitively, the distortion increases with the individual donor's bias up to the limit where the investment made in the unilateral project absorbs his whole budget.

The paper explores next the possibility for the recipient to impose a tax on the unilateral projects to limit the consequences of the uncoordinated behavior by multiple principals. To optimize the allocation of funds across the different projects the agent might charge each principal a tax proportional to the amount this principal wants to invest in his own unilateral project. At the optimum the tax rates are different from one project to the next, and therefore from one principal to the next, depending on the relative productivity of their unilateral projects. It is intuitive that if a share of these taxes is included as a benefit in the recipient objective function (either because of capture or of fiscal concerns) the optimal level of taxation is shifted upward. More surprisingly, even if the taxes are a pure waste of resources, their rates can still be positive as they act as a protection measure. By taxing the unilateral funds the recipient can correct for the principals' biases, and hence the loss of resources due to the taxes requested by the agent is compensated by an allocation of funds which is closer to the optimal coordinated level.

The paper therefore proposes a new tool to improve aid effectiveness that can inform the current debate on reforming the various tax exemptions of aid.

\footnotetext{
${ }^{8}$ For instance among the 3700 aid relationships tracked down in the OECD Development Co-operation Report (OECD (2008a)), 600 are micro-aid schemes of under USD 250000 per year each, and amounting to only $0.1 \%$ of country programmable aid. More generally in 2005-06, 38 partner developing countries had more than 25 official donors, most of them small. In 24 of these developing countries, 15 or more donors provided less than $10 \%$ of that country's total aid (OECD (2008b)).
} 
Taxation of aid funds by recipient countries is the focus of the discussions at the Platform for Collaboration on Tax and the Addis Tax Initiative. ${ }^{9}$ As Steel et al. (2018) report, official aid has often been exempted from national taxation, but donors have started to signal the incoherence between these tax exemptions and the goal to increase domestic revenue mobilization. While these exemptions date from international treaties signed when the multilateral institutions were created, some donors, such as the Netherlands or Norway, have already announced that they will abstain from requesting tax exemption on their aid transfers in the future. Our results should contribute to the reflection on how best to handle the current project-based tax negotiation between donors and recipient. One may wonder, how feasible it would be to implement different tax schemes for different projects? However, as detailed in Steel et al. (2018), the variance that currently exists in exemptions across tax categories (for example customs or VAT) and across beneficiaries of tax exemptions (for example employees of the implementing agencies, national or non-resident contractors) shows that it is technically feasible to implement a donor-project differential tax scheme as proposed here. For instance the recipient could make a list of projects that are prioritized, and therefore will benefit from a tax break. Non prioritized projects would be more heavily taxed. We could also imagine non linear taxation schemes, where micro-aid projects would be more heavily taxed than large ones so as to discourage cosmetic aid. From a policy perspective this mechanism is appealing as it is simple and might help to better align recipient and donors interest. Moreover the money collected could be used to improve recipient's country administrative capacity and help finance the administrative costs imposed by the management of fragmented aid on the recipient country.

The paper is organized as follows. Section 2 presents a review of the literature and provides empirical evidences to motivate the model. Section 3 presents the model. Section 4 studies the benchmark case of coordinated principals: principals' funds are pooled and a benevolent planner allocates them to different projects to maximize development returns. Section 5 presents the uncoordinated principal's setting and studies the optimal taxes that the agent should impose on the principals' unilateral project. Finally section 6 offers some concluding remarks.

\footnotetext{
${ }^{9}$ See http://www.worldbank.org/en/programs/platform-for-tax-collaboration and https://www.addistaxinitiative.net/ for details on these initiatives.
} 


\section{Literature on aid fragmentation and empir- ical evidences}

The literature on the adverse effects of donors fragmentation on aid effectiveness is extensive and has looked at the problem from different angles. The Rome Declaration on Harmonization signed in 2003 highlighted the need to harmonize the operational policies, procedures and practices of donor institutions with those of partner country systems to improve the effectiveness of development assistance. ${ }^{10}$ Transaction costs and problems on the coordination of projects controlled by a pool of donors have been the main concerns in the aid coordination literature, as summarized in Bigsten (2006) and in the recent survey by Gehring et al. (2017). Acharya et al. (2004) present a good description of the different measures of donor proliferation. Easterly and Pfutze (2008) analyze donor's distribution of funds among the many recipients and how it relates to good aid practices. Easterly and Williamson (2011) analyze the best and worse practices of aid agencies and the remedies donors should implement to alleviate the problem. Knack and Rahman (2008) highlight the problem of diffusion of responsibility between donors and the possible dis-alignment of incentives among them. They emphasize the need for recipients to be able to select a leader donor, and cite examples on recipients declining stand-alone projects. These examples show that recipients can take radical action (in this case turning down aid, which is equivalent to $100 \%$ taxation) to improve aid management. In what follow we take this point further by looking at optimal taxation.

Bobba and Powell (2006) open the black box of the cause of aid fragmentation, and show that donors face a trade-off between coordination costs and dilution of individual objectives when choosing between bilateral and multilateral contributions. Dreher and Kilby (2010) show that donors motives matter on aid effectiveness, and hence that private benefits from unilateral projects should be taken into account. Knack and Smets (2013) analyze the relationship between fragmentation and tying from the donor's side. They show that untying aid and reducing fragmentation turn out to be complementary interests for the donors. Consistently with these papers, in the model below donors are biased towards their unilateral project. In the choice between unilateral and coordinated contributions, they face a tradeoff between development goal and individual objective.

Knack and Rahman (2007a), Knack and Rahman (2008) and Knack (2013) explore the negative impact of donor fragmentation on recipient coun-

\footnotetext{
${ }^{10}$ See for example Balogun (2005) for the distinction between harmonization of procedures, alignment of objective and ownership.
} 
try bureaucratic quality and country administrative systems, given the internal competition for skilled labor. In our model we prove the existence of an upper bound on the donors' aggregate budget above which the recipient stops using the aid money. We coincide with Roodman (2006a) and Roodman (2006b) in highlighting that increasing aid budget does not necessarily lead to higher development production. In Roodman (2006a) and Roodman (2006b) the bound is given by the country's administrative capacity, while in ours it is endogenously determined based on the agent's management costs and the decreasing returns to scale of the development production function. We also find that the allocation of funds among projects in one sector can be unbalanced (either due to unbalanced aid budget between the donors or due to bias in donors' preferences). This result is a complement to HalonenAkatwijuka (2007) who study the allocation of funds among sectors to avoid donor concentration in some sectors and underfunding of others.

Finally another part of the literature focuses on the impact of aid fragmentation on rent-seeking activities. Djankov et al. (2009) study the impact of aid fragmentation on efficiency and corruption. Jones and Tarp (2016) explore the negative effect of donor diversity on recipient's political institutions. Minasyan et al. (2017) explore how donor's performance affects project effectiveness. Isaksson and Kotsadam (2018) and Brazys et al. (2017) show how unilateral Chinese projects increase corruption of recipient areas. Asongu (2012) and Okada and Samreth (2012) provide positive and negative evidence respectively on the correlation between received aid and recipients corruption. The focus of our analysis is not corruption, but, for the sake of realism, we take this possibility into account by looking at a recipient who can be biased in favor of 'taxing' the donors. This will typically be the case if she can capture a share of the taxes for private use.

The literature described above looks at the problems (causes and consequences) of aid fragmentation from the donors community perspective. The novelty of our approach is to look at the fragmentation problem from the recipient's point of view. ${ }^{11}$ Our paper is therefore complementary to the aforementioned literature as we explore the actions the recipient might take to discipline the donors and alleviate the problem posed by aid fragmentation. In our setting the recipient draws taxes (or administrative fees) for the implementation of unilateral projects as protection measures to inefficient donors' allocations. She does not reject unilateral projects if they are useless, she taxes them to reorient the aid flow where it is most needed. The tax

\footnotetext{
${ }^{11}$ There is a vast literature on aid contracting, including among others Azam and Laffont (2003), Svensson (2003), Morrissey et al. (2012), that works on conditionality. This literature also looks at the issue of aid effectiveness from the donors perspective: The problem is the recipient behavior and aid conditionality is a tool to control the use of aid.
} 
instrument therefore fills a double purpose. First it helps the recipient country to collect funds to strengthen its administrative capacity to overcome the problems illuminated by Roodman (2006a), Roodman (2006b), Knack and Rahman (2007a) and Knack and Rahman (2007b). Second it helps to align the interests of the donors with the interest of the recipient, which is a major challenge as shown, for instance, by Bobba and Powell (2006), Dreher and Kilby (2010) and Knack and Smets (2013). It is a stick used to keep the donors in line and to modulate their aid flows.

\subsection{Empirical evidences on aid fragmentation and on donors' bias}

The Paris Declaration on Aid Effectiveness (2005) was signed by more than 100 countries to reform the way in which international aid is delivered and managed. Following the Paris Declaration, the Accra Agenda for Action signatories committed to " reduce the fragmentation of aid by improving the complementarity of donors' efforts and the division of labour among donors, including through improved allocation of resources within sectors, within countries, and across countries". ${ }^{12}$

In Figure 1 (right panel) we show the rise in time of the average number of aid implementing agencies per recipient country: recipients have gone from dealing on average with 50 agencies in the eighties to dealing with 160 agencies in the last decade. Even if the evolution is partly due to improvement in reporting, the increase in number of implementing agencies is striking. The confidence intervals in the figure show that there is variance across recipients in the number of agencies to deal with, but the increasing trend is clear even for the lower bound of the interval. This increase in the number of agencies implies a multiplicity of projects to be dealt by each recipient. We present in Figure 1 (left panel) the average aid concentration index. We see that it has decreased sharply in time: from 0.20 in the eighties to 0.05 in the last decade. This decrease has been especially drastic for Sub-Saharan recipients (0.15 in the eighties to 0.02 last decade).

On the donor side, the 2008 OECD survey on monitoring the Paris Declaration (OECD (2008b)) was the first significant attempt to measure donor coordination problems. We present in Table A.1 a summary of the data published in this survey: only $21.5 \%$ of donor missions are coordinated, and only $37 \%$ of aid uses country systems, hinting an important lack of joint efforts

\footnotetext{
${ }^{12}$ See OECD (2008a) for more detail on the Accra Agenda for Action or http://www.oecd.org/dac/effectiveness/parisdeclarationandaccraagendaforaction.htm .
} 
Figure 1: Aid Fragmentation at the Recipient Level, 1980-2013
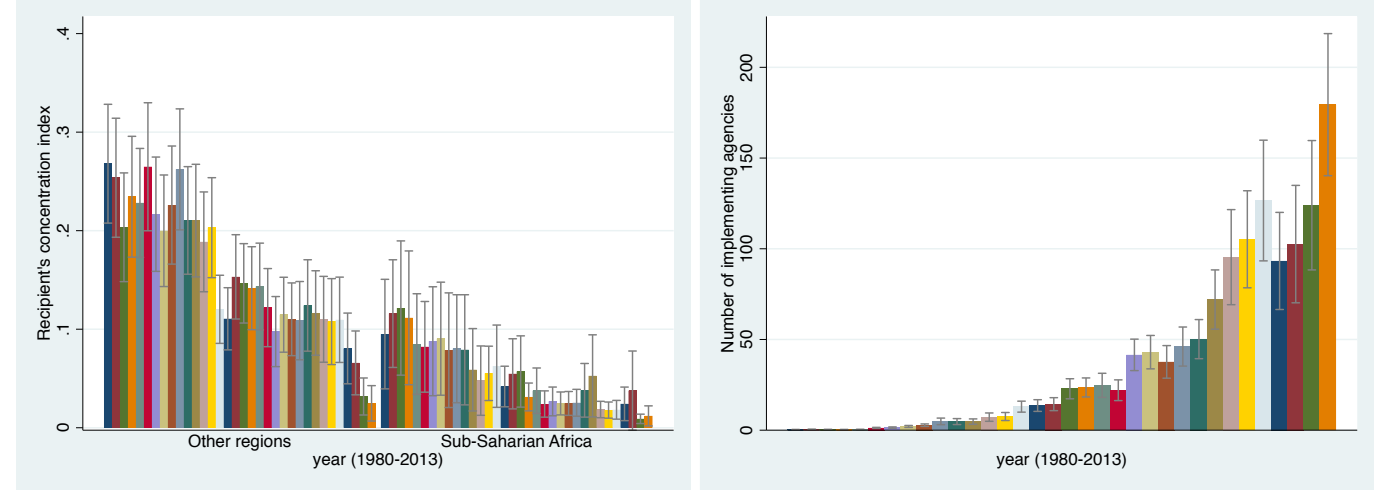

The Figures represent regions/world average value and show confidence intervals at $95 \%$. They cover 222 recipients. The concentration index is the sum of squares of the share that each agency represents in a recipient/year aid volume (i.e., a Herfindalh index decreasing with fragmentation).

Source: AidData. 2017 (AidDataCore, ResearchRelease 2017).

both at the planning and implementation of development projects.

The work of Knack (2013) is to the best of our knowledge the unique contribution to the aid literature using detailed data to analyze the choice of channel of delivery by donors considering both the recipient country system characteristics and the donor's preferences. To be more specific Knack (2013) aims to explain donors' decisions to trust (or not) recipients' country systems. He conducts empirical tests using data from three Paris Declaration Monitoring Surveys (PDMS), designed to monitor progress toward Paris Declaration goals, covering years 2005, 2007 and 2010. He approaches the trust in country systems as a public good: benefits to use and contribute to improve country systems are external (benefit other donors) and long term, while the costs are short term and covered by the donor using these systems. His tests show that a donors' use of the recipient country systems is correlated positively to the donor's share of aid provided to the recipient, negatively to perceptions of corruption in the recipient country, and positively to public support for aid in the donor country. In other words, recipient country systems are more used by donors with a strong popular support in favor of aid in their home country, a big share of the recipient's aid market, and for recipients with better institutional and trustworthy systems.

In the appendix A.2 we look at the OECD-DAC-CRS dataset for the periods 2010 and 2011, when a 'Donor Government' channel is introduced. This variable is crucial to us as it provides a measure of the volume of aid that is referred to as "unilateral" in the theory. We focus on Sub-saharan 
Africa and we use all aid projects received by Sub-Saharan African countries from multilateral and bilateral donors to check whether some correlations inspired by Knack (2013) analysis are still robust in our sub-sample.

Table A.2 in the appendix shows that donor's bias, measured by the share of donor's total aid using unilateral channel, is significantly (i.e., at the $1 \%$ level) and positively correlated with the use of the 'Donor Managed' channel of delivery. This result is robust to the inclusion of recipient, donor and year fixed effects, that control for different reporting behavior across years and across donors. It is also robust to the inclusion of other controls. Everything else being equal, biased donors, in Knack (2013) sense, are channeling to any recipient a greater share of their aid unilaterally (i.e. out of the recipient's country systems). We also find that not all recipients are treated in the same way by the donor community. There is indeed a strong positive correlation between the fact that any donor use more the donor managed channel and the share of total recipient's aid that is managed unilaterally (for more on this see appendix A.2). The result, which is robust to the introduction of donorrecipient-year fixed effects, is consistent with Knack (2013) findings that recipients are treated differently depending on whether they are perceived as trustworthy or not. In what follows we therefore consider that donors might be biased and that the recipient might be corrupted.

\section{The model}

In our setting we have $K$ principals (the donors), each conventionally a "he" denoted by $k=1, \ldots, K$, that provide funds to a unique agent (the recipient), conventionally a "she" denoted $r$. We consider two possible channels for the funds delivery:

- Unilateral aid projects, referred to as $k=1, \ldots, K$, implemented by the recipient government according to the principal's $k=1, \ldots, K$ established procurement rules.

- Pooling of funds, referred to as $p$, where all principals join efforts for the design and implementation of the project.

Let $B_{k}$ be the principal $k$ total aid budget, and let $p_{k}$ and $u_{k}$ be the amounts contributed to the pool and to the unilateral project respectively. For the unilateral project, the principal needs to pay a percentage $c_{k}$ of the value of the unilateral contribution to the recipient. That is, $c_{k}$ is the cost of the agent's pre-requisites for unilateral projects. It can be interpreted as a tax to cover the expenses of meetings with the recipient and bargaining. It 
is a tool to regulate the flow of aid that goes into unilateral aid. Hence, the budget constraint for principal $k=1, \ldots, K$ is given by:

$$
B_{k}=p_{k}+\left(1+c_{k}\right) u_{k}
$$

Funds are transferred by each principal to the agent. The total development outcome depends on the volume of aid which is allocated to each project. To keep the analysis simple we focus on a development production function of the Cobb-Douglas form with coefficients $\alpha_{p} \geq 0$ and $\alpha_{k} \geq 0(k=1, \ldots, K){ }^{13}$

$$
G(p, u)=p^{\alpha_{p}} \prod_{k=1}^{K} u_{k}^{\alpha_{k}}
$$

where

$$
p=\sum_{k=1}^{K} p_{k}
$$

denotes the total amount of funds in the pool and

$$
u=\left(u_{1}, \ldots, u_{K}\right)
$$

the vector of unilateral contributions.

We abstract from the optimization problem linked to non-convexity by ruling out increasing returns to scale.

$$
\sum_{k=1}^{K} \alpha_{k}+\alpha_{p} \leq 1
$$

The Cobb-Douglas function implies that independent projects cannot be successful in absence of the pooled activity, and that the pooled project cannot be successful without the support of the unilateral activities. For example, if pooled funds go to recurrent expenditures for hospitals and dispensaries, one of the donors has a unilateral program to fund medical supplies

\footnotetext{
${ }^{13}$ We focus on a Cobb-Douglas production function to keep the exposition simple as it yields closed form solutions. However our results are robust to production functions that are increasing and concave in the aid investments and exhibit complementarity in the different aid projects. In the limit the aid budgets are strictly complementary (i.e., Leontief production function). With such extreme production function our results are exacerbated as aid is wasted when the different budgets are not in the right proportion of each other. By contrast if all the aid projects are perfect substitutes (i.e., the development production function is proportional to the sum of all the aid money), it does not matter how much each donor puts in his "project" as they are all substitutable. This is a case where any allocation is efficient, conditional on the fact that the recipient can handle it.
} 
and pharmaceutical and the other funds a tutoring program for nurses and doctors, the independent projects cannot be successful if the hospitals and dispensaries are not open and running (i.e. if the pooled project is not successful), and the reverse argument also holds. Similarly in a situation where pooled funds go to recurrent education expenditures, one of the donors funds a unilateral nutrition program and the other donor funds a tutoring program, the unilateral projects cannot be successful if the school is not open and running, i.e. if the pooled project is not successful. The output education is only attained when the three projects work simultaneously. Each donor gets benefit from the development good produced plus additional rents from the unilateral project contributions. Hence, the contribution to the pool is a public good. Each donor has an incentive to wait for the other donor to contribute to get better returns on its own unilateral project. Yet someone has to put something in the pool to get results from the unilateral projects.

Finally in some cases the unilateral project of some principals might be useless to the recipient. Such useless projects are referred by the internet community discussing aid as 'SWEDOW' (for 'stuff-we-don't-want'). ${ }^{14}$ In this case the coefficients $\alpha_{k}$ corresponding to these useless unilateral projects will all be equal to 0 .

Let

$$
B=\sum_{k=1}^{K} B_{k} .
$$

be the aggregated budget from all principals. Since by virtue of (1)

$$
p=B-\sum_{k=1}^{K}\left(1+c_{k}\right) u_{k}
$$

and since $\alpha_{p} \leq 1$, the production function in (2),

$$
G(p, u)=G\left(B-\sum_{k=1}^{K}\left(1+c_{k}\right) u_{k}, u\right)
$$

is increasing and concave in $B$. That is, the greater the budgets the better, with decreasing returns.

\footnotetext{
${ }^{14}$ In kind aid of left overs is generally a poor match for the recipient needs. To illustrate what a SWEDON is, see for instance "Bad Charity? (All I Got Was This Lousy T-Shirt!)" By Nick Wadhams in Time May 12, 2010 available at http://content.time.com/time/world/article/0,8599,1987628,00.html
} 


\subsection{Principals' utility}

Principals care about the development outcome produced through their funds allocation but they also may derive utility from the visibility of their unilateral project and from the establishment of procurement rules that directly or indirectly benefit their own commercial and political interests. Principal's $k=1, \ldots, K$ utility has the form:

$$
U_{k}\left(u_{k}\right)=G(p, u)+\zeta_{k} H\left(u_{k}\right)
$$

Term $\zeta_{k} \geq 0$ is the bias in principal $k$ preference for his own unilateral project. The weight $\zeta_{k}$ decreases with altruism. It would be zero for a perfectly altruistic principal, or unbounded for a perfectly egoistic principal for whom development returns represent a negligible part of the utility. ${ }^{15}$ Term $H\left(u_{k}\right)$ is a strictly increasing and concave function of the unilateral contribution $u_{k}$ :

$$
H^{\prime}\left(u_{k}\right)>0 \text { and } H^{\prime \prime}\left(u_{k}\right) \leq 0
$$

Each principal maximizes (9) by choosing the allocation

$$
u_{k} \in\left[0, \frac{B_{k}}{1+c_{k}}\right]
$$

compatible with his budget constraint (1) and subject to the agent's individual rationality constraint that is derived below.

\subsection{Agent's utility}

The recipient chooses the level of the fee $c_{k} \geq 0$ to be paid by each of the principals $k=1, \ldots, K$ for the establishment of unilateral projects in the country. For the agent, this fee represents a reduction of the funds to be managed and hence a reduction in the cost of investment. As discussed in the aid literature, developing countries have limited administrative capacity. Managing many unilateral projects is very costly for them. In this context, the fees represent for the agent a relative utility gain when she does not have to manage all the unilateral aid funds, but only a fraction of them. The important point is that the fee is lost to the principal $k=1, \ldots, K$ and to the development project.

In practice this fee can be a real tax that helps financing public expenses. It might also represent the value of the perks when the agent uses part of the

\footnotetext{
${ }^{15}$ As Bobba and Powell (2006) show, donors face a trade-off between coordination costs and dilution of individual objectives when choosing between bilateral and multilateral contributions.
} 
received funds for private benefit (e.g. such as fancy SUV cars, trips, and restaurants). The fee might therefore bring some utility to the agent. As Williamson et al. (2008) point out, funding activities parallel to the pooled funds generate multiple material and non-material benefits for the ministers and civil servants of the sectors involved. To capture this idea we assume that the agent keeps a fraction $\Gamma \sum_{k=1}^{K} c_{k} u_{k}$ of the collected fees with $\Gamma \in[0,1)$. However our results are not driven by the fact that the agent is corrupted or greedy (i.e., they are robust to $\Gamma=0$ ).

The agent's cost of investing the received funds depends on the amount of funds to be managed. We assume that the cost function of managing funds, denoted $\Psi($.$) , is increasing and convex in the flows received. { }^{16}$ By virtue of (1), $p=B-\sum_{k=1}^{K}\left(1+c_{k}\right) u_{k}$. Agent's investment cost is given by the increasing and convex function:

$$
\Psi\left(p+\sum_{k=1}^{K} u_{k}\right)=\Psi\left(B-\sum_{k=1}^{K} c_{k} u_{k}\right) .
$$

Let

$$
G(B, u \mid c)=G\left(B-\sum_{k=1}^{K}\left(1+c_{k}\right) u_{k}, u\right)
$$

be the development produced, where

$$
c=\left(c_{1}, \ldots, c_{K}\right) .
$$

The agent's objective is to choose $c$, the vector of fee levels for handling unilateral funds, to maximize her utility given the principals' funds allocation. The agent's utility in case she chooses to invest the aid funds in the projects is given by ${ }^{17}$

$$
U_{r}(B, c)=G(B, u \mid c)-\Psi\left(B-\sum_{k=1}^{K} c_{k} u_{k}\right)+\Gamma \sum_{k=1}^{K} c_{k} u_{k}
$$

\footnotetext{
${ }^{16}$ We abstract here of interactions among the different projects on effort costs. For example, Knack and Rahman (2007a) study how recipient's bureaucratic quality is affected by donor's preferences and number of projects.

${ }^{17} \mathrm{It}$ is worth noting that even if they are fully benevolent (i.e. if $\zeta_{k}=0$ and $\Gamma=0$ ), the donors and the recipient do not have the same objective function. The donors do not internalize the administrative cost imposed by aid management. In practice administrative capacity is a public good, which yields problem of free-ridding: everybody would like the other to finance it. It is also a black box for the donors that could hide corruption. At least development outcome is a "clean" objective and is easier to sell politically to their constituencies (i.e., taxpayers in advanced economies). It is easier to communicate around new schools or new dams than around elusive "better state capacity".
} 
In case the agent chooses not to invest in any of the projects, her utility is 0 . To avoid wasting the funds the agent individual rationality constraint must be satisfied:

$$
U_{r}(B, c) \geqslant 0
$$

The agent receives benefits from the output produced with the transferred funds that cannot be appropriated by the principal. In comparison with the standard moral hazard models, the principal has one instrument less since he cannot choose the share of the 'public good' produced that can be appropriated by the agent: here the production of development is enjoyed in a non-excludable way by both the principals and by the agent. This is in contrast to what usually occurs in piece rates or sharecropping agreements. Hence, it is likely that when the development outcome is high so that investment gives large returns to the agent, the participation constraint does not bind.

Timing is as follows:

1. The agent announces $c=\left(c_{1}, \ldots, c_{K}\right)$ (with $c_{k} \geq 0$ for all $k=1, \ldots, K$ ), the vector of cost to be paid by the principals for the management of their unilateral projects.

2. Each donor chooses simultaneously the share of his budget to be allocated to the pool and the share to be allocated to the unilateral project.

3. The recipient takes the decision of whether or not to invest the funds in the development project.

In our model, both the agent-recipient and the principals-donors take decisions, namely the costs for unilateral projects and the allocation of funds, that affect the development returns from a given budget. In our case, agent's contribution to the production is her choice of using the aid money in a productive way, and is a necessary ingredient for aid effectiveness. Moreover, waste of aid resources in the form of a tax comes from agent's choices and is imposed on the principals, in contraposition to the usual approach of only considering administrative burdens on agents. It is a tool to better align donors and recipient interests. Since the objective functions of the recipient and of the donors are not aligned, and since all of them make decisions that influence the development outcome, the solution to the aid allocation game is quite complex. We first solve the benchmark case where principals coordinate their allocation of funds. 


\section{Benevolent planner's problem}

In this section we derive the first best solution from a centralized and benevolent planner point of view. We assume the principals pool all their resources and then choose the allocation to each type of project so as to maximize aggregate development returns $G$. In this case the budget constraint when all principals funds are merged is

$$
B=\sum_{k=1}^{K}\left(1+c_{k}\right) u_{k}+p
$$

where $p$ represents the total funds that go to the pool and $u_{k}$ the funds that go to the projects implemented unilaterally by principal $k=1, \ldots, K$. The principals transfer aid money if the development project is worthwhile for the agent. No fund is transferred otherwise.

On a totally coordinated setting, the planner maximizes development returns. The benevolent planner solves

$$
\max _{u} G(B, u \mid c)=\left(B-\sum_{k=1}^{K}\left(1+c_{k}\right) u_{k}\right)^{\alpha_{p}} \prod_{k=1}^{K} u_{k}^{\alpha_{k}}
$$

under the aggregated budget constraint (14). Since $\alpha=\sum_{k=1}^{K} \alpha_{k}+\alpha_{p} \leq 1$, the optimal allocation of funds is given by

$$
\begin{aligned}
u_{k}^{*} & =\frac{\alpha_{k}}{\alpha} \frac{B}{1+c_{k}} \quad k=1, \ldots, K \\
p^{*} & =\frac{\alpha_{p}}{\alpha} B
\end{aligned}
$$

Development outcome is given by

$$
G^{*}(B, c)=\prod_{k=1}^{K}\left(\frac{\alpha_{k}}{1+c_{k}}\right)^{\alpha_{k}} \alpha_{p}^{\alpha_{p}}\left(\frac{B}{\alpha}\right)^{\alpha}
$$

that is concave in the budget $B$ given the non increasing return to scale assumption $\alpha \leq 1$. The agent's utility when she takes into account the benevolent planner's optimal allocation (15) is given by:

$$
U_{r}(B, c)=G^{*}(B, c)-\Psi\left(B-\sum_{k=1}^{K} \frac{c_{k}}{1+c_{k}} \frac{\alpha_{k}}{\alpha} B\right)+\Gamma \sum_{k=1}^{K} \frac{c_{k}}{1+c_{k}} \frac{\alpha_{k}}{\alpha} B
$$

To make the analysis interesting we focus on cases where the agent is willing to take the aid funds and use them in a productive way rather than to simply 
turn them down. This requires that condition (13) holds for some value of the parameters, and thus that the function $\Psi(B)$ is relatively small compared to $G^{*}(B, 0)$, at least for some value of $B$. Let

$$
\Omega=\frac{\prod_{k=1}^{K} \alpha_{k}^{\alpha_{k}} \alpha_{p}^{\alpha_{p}}}{\alpha^{\alpha}}
$$

We assume in the sequel of the paper that $\Psi(0)=\Psi^{\prime}(0)=0$ and that $\lim _{B \rightarrow+\infty}\left\{\Omega B^{\alpha}+\Gamma B-\Psi(B)\right\}<0$ so that there exists a strictly positive value of $B$, denoted $\bar{B}_{\Gamma}$, such that

$$
\Omega B^{\alpha}+\Gamma B=\Psi(B)
$$

For the sake of interpretation it is convenient to assume that $\Psi(B)$ is initially sufficiently small so that $\bar{B}_{\Gamma}>>0$ (i.e., $\bar{B}_{\Gamma}$ is large). For instance if $\alpha=1$ and $\Psi(B)=\frac{B^{2}}{2 \psi}$, then $\bar{B}_{\Gamma}=2 \psi(\Omega+\Gamma)$, which is large if $\psi$ is a large number. This example also illustrates that $\bar{B}_{\Gamma}$ increases with $\Gamma$.

Under our assumptions ( $\alpha \leq 1$ and $\Psi($.$) strictly increasing and convex),$ the function $\Omega B^{\alpha}+\Gamma B-\Psi(B)$ is strictly concave. Moreover, since $\Psi^{\prime}(0)=0$, it is strictly increasing when $B \rightarrow 0^{+}$and since $\lim _{B \rightarrow+\infty}\left\{\Omega B^{\alpha}+\Gamma B-\right.$ $\Psi(B)\}<0, \bar{B}_{\Gamma}>0$ exists. The agent has no incentive to waste the money at the optimum whenever $B \leq \bar{B}_{\Gamma}$ (i.e., agent's individual rationality constraint holds). If the principals choose to give much more than $\bar{B}_{\Gamma}$ the extra aid money is wasted as the agent is not willing (unable) to handle it. Let $\bar{B}_{\Gamma}$ be defined by equation (20). The next assumption helps us to rule out aid money wasting.

A1

$$
B \leq \bar{B}_{\Gamma}
$$

We also deduce that there exists a value of $B$, lower than $\bar{B}_{\Gamma}$ so that $\Omega B^{\alpha}+\Gamma B-\Psi(B)$ is maximal. Let $B_{\Gamma}^{*}>0$ be the coordinated budget that optimizes $\Omega B^{\alpha}+\Gamma B-\Psi(B)$. It is such that

$$
\alpha \Omega B^{-(1-\alpha)}+\Gamma=\Psi^{\prime}(B) .
$$

We have $0<B_{\Gamma}^{*}<\bar{B}_{\Gamma}$. Given the planner's allocation of funds, the agent chooses whether to ask for special fees for unilateral projects, i.e. she optimizes on the choice of $c=\left(c_{1}, \ldots, c_{K}\right)$. The optimal agent's decision depends on the trade-off between the benefits of these fees (i.e., decrease in investment/management costs) and the loss of development outcome.

The agent's utility (18) is not necessarily concave in $c=\left(c_{1}, \ldots, c_{K}\right)$. Indeed the function $G^{*}(B, c)$, which is decreasing in each $c_{k} k=1, \ldots, K$, is 
convex in $c$, while the function $-\Psi\left(B-\sum_{k=1}^{K} \frac{c_{k}}{1+c_{k}} \frac{\alpha_{k}}{\alpha} B\right)+\Gamma \sum_{k=1}^{K} \frac{c_{k}}{1+c_{k}} \frac{\alpha_{k}}{\alpha} B$ is increasing and concave in $c$. This implies that we do not necessarily get an interior solution. The next proposition derives the optimal tax structure when the agent faces coordinated principals.

Proposition 1 (optimal taxes with coordinated principals) Under assumption $A 1$ the agent sets a uniform $c_{k}=t^{*}>0 \forall k \in\{1, \ldots, K\}$ solution to

$$
\Psi^{\prime}\left(B \frac{\alpha+\alpha_{p} t}{\alpha(1+t)}\right)+\Gamma=\alpha B^{\alpha-1} \Omega(1+t)^{1-\sum_{k=1}^{K} \alpha_{k}}
$$

if and only if $B \in\left[B_{\Gamma}^{*}, \bar{B}_{\Gamma}\right]$ where $\bar{B}_{\Gamma}$ is defined equation (20) and $B_{\Gamma}^{*}$ equation (21). She sets $t^{*}=0$ otherwise.

Proof. See the appendix A.3.

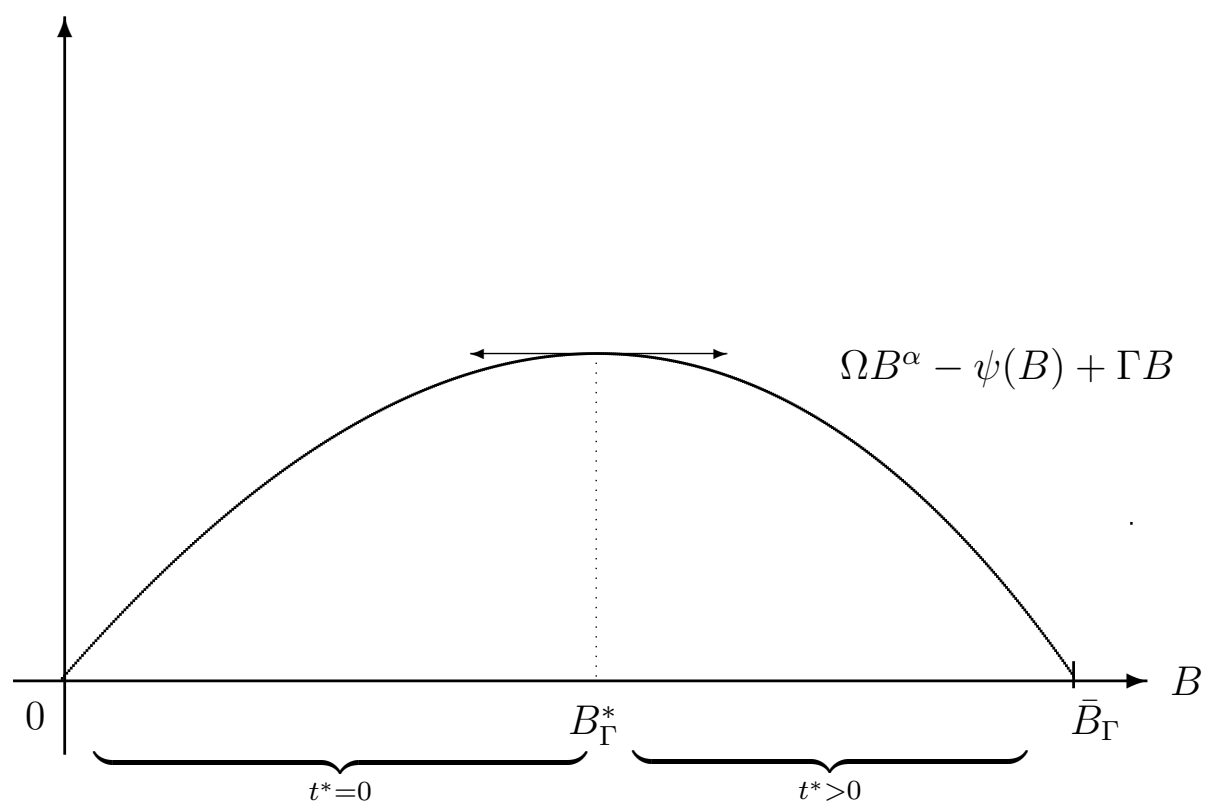

Figure 2

Figure 2 illustrates the result of Proposition 1. The agent would be willing to choose different $c^{\prime} s$ for the $K$ unilateral projects according to their relative productivity, but that is already accounted for by the coordinated principals' allocation so that at the optimum they are equal. When the total budget of the principals is lower than $B_{\Gamma}^{*}$ the cost of managing the funds is sufficiently low so that the agent does not want to charge positive fees. The agent puts a distortion on the allocation to unilateral projects when 
the marginal benefit from increasing $c$ over zero in terms of investment cost reduction and in term of bribes/perks is greater than the marginal loss in terms of development outcome, which occurs when $\Psi^{\prime}(B)>\alpha B^{\alpha-1} \Omega+\Gamma$. For instance with $\alpha=1$ (i.e., constant returns to scale) the condition is simply $\Psi^{\prime}(B)>\Omega+\Gamma$. The condition holds more easily when the global budget $B$ is large and/or when the unilateral projects have a relative low effect on the development production function (i.e., when some $\alpha_{k}$ are small so that $\Omega$ is small) and the share of fees that the agent can keep is large (i.e., $\Gamma$ is large). This first result illustrates that, even if the principals are fully coordinated and altruistic and $\Gamma=0$, there is a benefit for the recipient to charge strictly positive fees. When the agent is not keeping a percentage of the fees, she still might want to implement a positive tax to reduce the burden of managing the funds unilaterally. The principals focus on development outcome and they neglect the administrative burden the management of these funds imposes on the recipient. The later imposes a tax on the unilateral funds to oblige the principals to internalize this cost.

From a policy perspective Proposition 1 implies that, everything else being equal, recipients getting more aid (i.e., larger $B$ ) should request strictly positive fees $t^{*}>0$, even in the fully coordinated case. Moreover totally differentiating (22) one can check that the fee $t^{*}$ is increasing with $B$ and with $\Gamma$. In other words, Proposition 1 implies that the fee requested by the recipient should be increasing with the amount of aid received and the level of rent she can extract from them. It is intuitive that the more the agent can keep from the taxes, the more she is willing to implement them.

\section{Independent principal's choice}

We are now turning to the more realistic case of uncoordinated principals. Our goal is to compare the independent principals' choice with the first best outcome derived in the previous section where all funds were pooled and allocated to the several projects by an output-maximizing planner. In doing so, we want to study how principals' and agent's choices affect development outcomes. On the one hand, we look at the loss in output due to the distribution of budgets among the donors and their biased preferences towards unilateral projects. On the other hand, we want to check in which situations the taxes on unilateral projects imposed by the agent are output increasing and hence their 'waste' is compensated by a better choice of channel of delivery by the principals.

When choosing the channel of delivery for aid funds, the principals' problem differs from the benevolent planner's in several aspects: 
1. Each principal is constrained by his own budget to allocate funds to the unilateral and pooled projects, while the benevolent planner may allocate freely the sum of funds between the different alternatives.

2. Principal's preferences may differ from the benevolent planner's preferences: The principals may have biased preferences as they obtain special benefit from their own unilateral projects.

3. The pool funding is a public good, which increases the productivity of all the unilateral projects. Hence, there may be a free riding problem when each principal optimizes his objective function independently.

We present a special case of common agency: we have $K$ principals that use a common agent to achieve a development goal. In our case, common agency is not a problem of which actions to incentive, as in Bernheim and Whinston (1986), but a problem of how funds are allocated by each principal to maximize his investment returns and how these decisions affect the agent's incentive to charge positive fees on the unilateral projects. Given the complementarity among the different projects, the principals agree on that the agent should use the funds to finance all projects. They might however disagree on the amounts that should be invested in each of them.

\subsection{Principals' allocation problem}

We start the analysis with the case of altruistic principals: $\zeta_{k}=0$ for all $k=1, \ldots, K$. The principals' objective functions are identical but the budget constraints are different because in general $B_{k} \neq B_{j}$ for $k \neq j$ :

$$
\begin{gathered}
\max _{u_{k}} G(B, u \mid c) \\
\text { s.t. } \quad B_{k}=p_{k}+\left(1+c_{k}\right) u_{k} \\
G(B, u \mid c)-\Psi\left(B-\sum_{k=1}^{K} u_{k} c_{k}\right) \geqslant 0
\end{gathered}
$$

The first constraint is the principal's budget constraint, while the second constraint is the agent individual rationality constraint. We next show that even if the principals have exactly the same objective function an uneven distribution of aid budgets can generate aid inefficiency.

Proposition 2 (uncoordinated allocation with altruistic principals) Let assumption $A 1$ hold and let $\alpha_{k}>0 \forall k \in\{1, \ldots, K\}$. When principals are 
altruistic the allocation of resources coincides with the coordinated optimal solution if and only if for all $k \in\{1, \ldots, K\}$

$$
\frac{\alpha_{k}}{\alpha}=\frac{B_{k}}{B}
$$

Proof. See the appendix A.4.

Condition (23) is intuitive: to reach the first best allocation in the uncoordinated case it is necessary that the funds are distributed among donors proportionally to the productivity of their different projects. Hence, inefficiencies might arise not because of divergence in preferences between principals but simply because of an unbalanced distribution of funds with respect to the relative productivity of the unilateral projects.

We now turn to the case where the principals have biased preferences, due for example to good publicity of the initiative, or to the extra benefit a principal gets from using his own procurement rules. The parameter $\zeta_{k}>0$ determines the value for principal $k$ of his own unilateral project. Principal's $k$ problem is

$$
\begin{gathered}
\max _{u_{k}} G(B, u \mid c)+\zeta_{k} H\left(u_{k}\right) \\
\text { s.t. budget constraint (1) } \\
\text { agent's IR (13) }
\end{gathered}
$$

Proposition 3 (unilateral allocations as strategic substitutes) When the principals have biased preferences towards their unilateral project, the contributions to their unilateral project are 1) strategic substitutes and 2) increasing with the principals' bias.

Proof. See the appendix A.5.

Contribution to the pool is a public good, and given that unilateral projects provide private benefits, it is in the interest of a principal to decrease its pool contribution when the amount contributed by the other principals increases. Since everything else being equal contribution to the pool increases with a donor budget, we deduce that donors with large aid budget contribute more to the pool than donors with small budget. Distortion with respect to the coordinated allocation is greater the greater is the principal's benefit from unilateral projects (i.e., the larger $\zeta_{k} \geq 0$ ). Indeed if the principal has a bias for his unilateral project, he will put more resources into it and less into the common pool: everything else being equal, a biased principal will contribute less often to the pooled than an altruistic one. 
We deduce from this analysis two implications: First, the principal's allocation of funds towards unilateral projects is increasing with the principals' bias (i.e., $u_{k}$ is increasing in $\zeta_{k}$ ). Second, everything else being equal, large donors contribute more to the pool than small ones. The results of Knack (2013) empirical analysis and of table A.2 are in line with the intuition of our model: first less-biased donors (e.g., donors with less pressure at home to justify how their aid is spend) make more use of recipient country systems and second donors whose transfers are an important part of the recipient's budget make also more use of recipient country systems. For instance, 84.7\% of 2007 Sudan's Official Development Assistance came from bilateral donors and from it $60 \%$ was managed through multilateral coordination. But when looking at the channel choice of each donor, we find that while Germany, a relatively small donor to Sudan, pooled $20 \%$ of its budget, Netherlands, one of the top donors, did pool $83.7 \%$ of his. Angola, on the other hand, received $66.7 \%$ of his ODA as bilateral in 2007, and only $16 \%$ of it was coordinated. When looking at the detail, Japan, a top donor, pooled $50 \%$ of his funds, while Switzerland, a small donor to Angola, only pooled $0.7 \%$ of its aid.

\subsection{Agent's reaction: choice of $c=\left(c_{1}, \ldots, c_{K}\right)$}

The agent needs to decide whether to ask for special fees for the unilateral projects to the different principals. To do so, the agent takes into account the type of the principals she is facing. When she faces $K$ altruistic principals, the agent's problem is the same as in the benevolent planner's case of section 4 as long as the distribution of budgets is such that first best allocation is attainable. In order to study the impact of bias in principals preferences, we assume in this section that condition (23) holds. If distortion in the choice of $c=\left(c_{1}, \ldots, c_{K}\right)$ occurs compared to the solution of Proposition 1 it is because the principals have biased preferences. Moreover we also assume that the bias in principals' utility function is linear in the amount invested in the unilateral project: $H(u)=u$. The linearity assumption simplifies the exposition. By continuity our result holds for a strictly concave function.

Proposition 4 (asymmetric fees with symmetric bias) Assume that (23) holds, that $H(u)=u$, and that the principals have symmetrically biased preferences towards their unilateral projects, $\zeta_{k}=\zeta$ for all $k \in\{1, \ldots, K\}$. Then, unless $\alpha_{k}=\alpha_{i}$, it is not possible to have $c_{k}=c_{i}$ for $k, i \in\{1, \ldots, K\}$.

Proof. See the appendix A.6.

Proposition 1 established that the fees are symmetric when all principals are altruistic. An important issue from a policy perspective is whether this 
result still holds when the principals have biased preferences. It is indeed important to check whether the recipient should be allowed to apply different taxes to different donors or not. Proposition 4 shows that the optimal fees are generally not symmetric with biased principals. Even if all the principals have symmetrical preferences the fact that they are biased towards their unilateral project generally kills the symmetry of the recipient solution in fees because the unilateral projects are not equally beneficial in terms of the development outcome.

To illustrate this result assume that $\Gamma=0, K=2$ and that the unilateral project provided by one of the principals, principal 2 without loss of generality, has no effect on development outcome (i.e., it is a SWEDOW): $\alpha_{2}=0$. The development production function is $G\left(u_{1}, p\right)=u_{1}^{\alpha_{1}} p^{\alpha_{p}}$ with $\alpha_{1}+\alpha_{p} \leq 1$. Even if $\zeta_{1}=\zeta_{2}=\zeta>0$, it is intuitive that the agent will choose a fee for project 2 that is higher than for project 1 , simply to discourage the waste of investing in project 2 . The agent sets a fee for principal 2 as big as necessary to ensure that his contribution to the unilateral project is zero. ${ }^{18}$

From the principal 1 point of view, there is then in the pool an amount $B_{2}$ of funds as budget support, which allocation is exogenous of any strategic interest. This situation is equivalent to the case where there is only one principal and one agent. The principal 1 optimization problem is the following:

$$
\begin{gathered}
\max _{u_{1}} u_{1}^{\alpha_{1}} p^{\alpha_{p}}+\zeta H\left(u_{1}\right) \\
\text { s.t. } p=B_{2}+B_{1}-\left(1+c_{1}\right) u_{1} \\
u_{1} \leqslant \frac{B_{1}}{1+c_{1}}
\end{gathered}
$$

where (26) is the principal's budget constraint, and (27) sets the constraint on the maximum unilateral allocation feasible for the principal. Let's substitute (26) into the principal objective function:

$$
\max _{u_{1}} u_{1}^{\alpha_{1}}\left(B_{2}+B_{1}-\left(1+c_{1}\right) u_{1}\right)^{\alpha_{p}}+\zeta H\left(u_{1}\right)
$$

Neglecting (27) we define $\hat{u}_{1}$ as the unconstrained solution to (28). Deriving (28) we obtain that $\hat{u}_{1}$ is solution to:

$$
\alpha_{1} u_{1}^{\alpha_{1}-1} p^{\alpha_{p}}-\left(1+c_{1}\right) \alpha_{p} u_{1}^{\alpha_{1}} p^{\alpha_{p}-1}+\zeta H^{\prime}\left(u_{1}\right)=0
$$

Let $\hat{u}_{1}$ be defined in equation (29). The principal investment in the unilateral project is

$$
u_{1}^{*}=\min \left\{\hat{u}_{1}, \frac{B_{1}}{1+c_{1}}\right\} .
$$

${ }^{18}$ To get $u_{2}^{*}=0$ requires $c_{2}$ to be so that $\frac{\partial U_{2}\left(u_{1}, u_{2}\right)}{\partial u_{2}}=-\left(1+c_{2}\right) \alpha_{p} u_{1}^{\alpha_{1}} p^{\alpha_{p}-1}+\zeta H^{\prime}\left(u_{2}\right)<0$. 
Replacing $p=B_{2}+B_{1}-\left(1+c_{1}\right) u_{1}$ by its value and totally differentiating (29), under the assumption $H^{\prime \prime}(u) \leq 0$, it is straightforward to check that $\hat{u}_{1}$ increases with $\zeta$, and with $B_{2}$. The principal contribution to the pool decreases with $\zeta$ (i.e., $\hat{u}_{1}$ increases with $\zeta$ ). This result is a reminiscence of the result in Proposition 3 (i.e., when the strategic interactions between the two principals are taken into account). Moreover $\hat{u}_{1}$ increases with $B_{2}$ which means that his contribution to the pool decreases with the exogenous amount of funds available in the pool. In fact the principal contributes to the pool only when the resources that are already in the pool are relatively small in comparison to his budget. This result is robust to the case where the principal is unbiased. ${ }^{19}$

We have shown in Proposition 4 that unless everything is symmetrical (i.e., the bias and the productivity of the unilateral project) the optimal solution is asymmetric. This result is reinforced when the biases are different. This is a case where the optimal fees are generically unequal. We deduce the following result.

Corollary 5 If the principals have biased preferences then in general $c_{k}^{*} \neq c_{i}^{*}$ for $k \neq i$.

We elaborate on the previous example with two principals to illustrate Corollary 5. We assume that, not only $\alpha_{2}=0$ and $\Gamma=0$, but also that $\zeta_{1} \neq \zeta_{2}>0.5$. To derive a closed-form solution we further assume that $\alpha_{1}=\alpha_{p}=0.5, H(u)=u$, and $B_{1}=B_{2}=B / 2<B_{\Gamma}^{*} / 2$ with $B_{\Gamma}^{*}=\Psi^{\prime-1}(0.5)$ being computed from (21). That is, at the first best solution the optimal investment levels are $u_{1}^{*}=B / 2, u_{2}^{*}=0$ and $p^{*}=B / 2$, which yields for the recipient the utility $U_{r}\left(u_{1}^{*}, u_{2}^{*}, p^{*}\right)=\frac{B}{2}-\Psi(B)$. We next show that the agent can by differentiating $c_{1}$ and $c_{2}$, decentralize this first best solution.

The agent needs first to set a fee for principal 2 as big as necessary to ensure that his contribution to the unilateral project is zero. We are thus left with a corner solution where $u_{2}^{*}=0$ which requires $c_{2}$ to be such that

$$
\frac{\partial U_{2}\left(u_{1}, u_{2}\right)}{\partial u_{2}}=-\frac{1+c_{2}}{2} \sqrt{\frac{u_{1}}{p}}+\zeta_{2}<0
$$

The best response functions of principal 1 is

$$
\frac{\partial U_{1}\left(u_{1}, u_{2}\right)}{\partial u_{1}}=\frac{1}{2} \sqrt{\frac{p}{u_{1}}}-\frac{1+c_{1}}{2} \sqrt{\frac{u_{1}}{p}}+\zeta_{1}=0
$$

${ }^{19}$ When $\zeta=0,(29)$ yields $\hat{u}_{1}=\frac{\alpha_{1}}{\alpha_{1}+\alpha_{p}} \frac{B_{2}+B_{1}}{1+c_{1}}$ so that $\hat{u}_{1}$ increases with $B_{2}$, while for (27) to be satisfied it requires that $B_{1} \geqslant \frac{\alpha_{1}}{\alpha_{p}} B_{2}$. 
Substituting $u_{2}^{*}=0$ in $(32)$ we deduce that ${ }^{20}$

$$
u_{1}^{* *}=\frac{B}{2\left(1+c_{1}+\zeta_{1}^{2}-\zeta_{1} \sqrt{1+c_{1}+\zeta_{1}^{2}}\right)} \geqslant \frac{B}{2\left(1+c_{1}\right)}
$$

but $u_{1}^{* *}$ is not feasible: principal 1 would be willing to spend more than his funds in his unilateral project since he obtains private benefits from it and principal 2 is already allocating all his budget to the pool. Hence, he is constrained by his resources so that

$$
u_{1}^{*}=\frac{B}{2\left(1+c_{1}\right)}, u_{2}^{*}=0
$$

will be the equilibrium as long as

$$
c_{2}>2 \zeta_{2} \sqrt{1+c_{1}}-1
$$

The optimal solution is then $c_{1}^{*}=0$ and $c_{2}^{*} \geq 2 \zeta_{2}-1>0$. By differentiating $c_{2}$ from $c_{1}$ the recipient is able to decentralize the first best outcome.

This result is not possible when both unilateral projects are needed for the production of development (i.e., when $\alpha_{1}>0$ and $\alpha_{2}>0$ ). In this case there is no tax structure that permits to decentralize the first best outcome, because to discourage the principals to over-invest in their unilateral projects the recipient has to tax the aid money invested unilaterally. This is a waste of resources compared to the first best outcome and the development level is lower. Nevertheless the creation of taxes on unilateral projects helps to bring the equilibrium closer to the first best. It improves the development outcome compared to a situation purely managed by uncoordinated donors.

\section{Discussion}

In this paper we analyzed a $K$ donors - one recipient model where both donors and recipients value the development outcome. Donors have to decide how to allocate their budget between a pool of funds and their unilateral project. The originality of our approach is to study how the recipient through her choice of taxes on the implementation of unilateral projects can affect

\footnotetext{
${ }^{20}$ We set $x=\sqrt{\frac{p}{u_{1}}}$ and solve the second order equation $(32): x^{2}+2 \zeta_{1} x-\left(1+c_{1}\right)=0$. Taking the square of the only positive root, yields $\frac{p}{u_{1}}=\left(\sqrt{1+c_{1}+\zeta_{1}^{2}}-\zeta_{1}\right)^{2}$. Substituting $p=B-\left(1+c_{1}\right) u_{1}$ in this equation and solving it yields $u_{1}^{* *}$ in $(33)$.
} 
the donors choice of channel of delivery and through that the development returns.

We find that, even when the donors are altruistic, their allocation of funds may differ from the fully integrated benevolent social planner's choice due to an unbalanced distribution of resources between them. This result illuminates that, even if the donors are unbiased and benevolent, their heterogeneity and lack of coordination in funds yields inefficiencies. This result militates against micro-aid schemes (i.e., cosmetic aid) and for a better coordination of donors ahead of the transfer of funds to help the recipient to allocate the aid resources efficiently. The Nordic Plus group, which include Denmark, Finland, Norway, Sweden, Ireland, the Netherlands, and the United Kingdom, is a good example of this type of donors coordination. The group is committed to improve aid effectiveness through Joint Financing Arrangements, Joint Procurement Policy, and Complementary Principles. The purpose is to exploit complementarities among the members of the group, through division of labor based on comparative advantages, to reduce the number of sectors and countries each donor operates in (NORAD, 2006) ${ }^{21}$

By contrast when the donors are biased, they tend to 'free ride' on each others contribution to the pool of funds. They increase their contribution to their unilateral project in an inefficient way as it provides greater private benefits to them than to the recipient. To correct this over-investment bias the recipient might impose taxes on the unilateral projects. Even if the taxes are lost to the development project, they help to correct the distortions imposed by the principals' biased preferences and therefore increase aid efficiency.

Taxation is a simple and effective tool to correct for negative externalities. However, in the case of aid, its implementation may be challenging. On the one hand, such a taxing mechanism requires full information on budgets and projects impact, and is implicitly ruling out the possibility of collusion between donors or between the recipient and one of the donors (for example in the form of corruption to government officials). On the other hand, our analysis implies that the tax rates imposed on unilateral aid should be different depending on donors' bias and on the productivity of their unilateral projects. The question of whom is going to set and to collect these taxes is crucial. In the theory the recipient is in charge of designing the tax rate and might capture a share of it. In practice the evidence suggests that the donor community deals with the problem of bad governance and low trustworthiness by relying on the unilateral channel of aid delivery. They control

\footnotetext{
${ }^{21}$ http://www.norad.no/globalassets/import-2162015-80434-am/www.norad.nony/filarkiv/vedlegg-til-publikasjoner/nordic-plus - practical-guide-to-delegatedcooperation1.pdf
} 
the way their aid is spent when they fear that it can be diverted into bribes. Allowing the recipient country to tax the unilateral aid with arbitrary tax rates will simply provide corrupt officials with a new tool to extract more money. A better solution would be to negotiate these corrective taxation rates at the international level.

While at the very early stage (both were created in 2016), the Addis Tax Initiative and the Platform for Collaboration on tax are promising. They show that the donors community is agreeing on the fact that aid taxation is an alley worth to explore. Our results should contribute to the reflection on how best to handle the current project-based tax negotiation between donors and recipient. The donors community should explore the possibility to tax bilateral aid to reduce fragmentation and to strengthen recipient countries administrative capacity. If it is unlikely that the donors will agree on different tax rates for different donor countries, they might agree to different tax rates for prioritized projects versus non-prioritized ones. The unilateral projects falling in the prioritized category could be offered special tax exemption, in contrast to unilateral projects not prioritized by the recipient's government. Similarly the tariffs should not be linear in the volume of aid transferred: very small aid volumes should be taxed more heavily so as to discourage aid fragmentation and the associated problem of aid unbalance analyzed in the paper. One may wonder, how feasible it would be to implement different tax schemes for different projects? However, as detailed in Steel et al. (2018), the variance that currently exists in exemptions across tax categories (for example customs or VAT) and across beneficiaries of tax exemptions (for example employees of the implementing agencies, national or non-resident contractors) shows that it is technically feasible to implement a donor-project differential tax scheme as proposed here. Some donors, such as the Netherlands or Norway, have started to signal the incoherence between these tax exemptions and the goal to increase domestic revenue mobilization. They have already announced that they will abstain from requesting tax exemption on their aid transfers in the future.

Taking action against poverty through micro aid projects can make it appear as if something has been done to address the issue of economic development, while in reality it would be more efficient to address the problem by pooling funds. And clearly, it does not make much sense to introduce an inconsistent or dysfunctional aid strategy unless it is merely a window-dressing initiative intended to impress voters. If the donor community is sincere in its willingness to fight fragmentation and improve aid efficiency it should explore the possibility for recipient countries to use tax instruments to improve aid coordination. Securing the adhesion of the donors at the international level is crucial. Without that there could be a concern that imposing taxes (or 
removing tax exemptions) would make the donors shop around for the best deals. That would discourage the recipients to consider such a corrective taxing scheme in the first place. 


\section{References}

Acharya, A., Fuzzo de Lima, A., and Moore, M. (2004). Aid proliferation: How responsible are the donors? IDS Working paper.

Asongu, S. A. (2012). On the effect of foreign aid on corruption. Economics Bulletin, 32(3):2174-2180.

Azam, J.-P. and Laffont, J.-J. (2003). Contracting for aid. Journal of Development Economics, 70(1):25 - 58.

Balogun, P. (2005). Evaluating progress towards harmonization. DFID Working paper.

Bernheim, B. D. and Whinston, M. D. (1986). Common agency. Econometrica, 54(4):923-942.

Bigsten, A. (2006). Donor coordination and the uses of aid. Working paper.

Birdsall, N. (2005). Seven deadly sins: Reflections on donor failings. Working paper GDN.

Bobba, M. and Powell, J. (2006). Multilateral intermediation of foreign aid: What is the trade-off for donor countries? Inter-American Development Bank working paper.

Brainard, L. (2007). Organizing us foreign assistance to meet twenty first century challenges. in L. Brainard, ed., "Security by other means: foreign assistance, global poverty, and American leadership", Brookings Institution Press, Washington, DC.

Brazys, S., Elkink, J. A., and Kelly, G. (2017). Bad neighbors? how colocated chinese and world bank development projects impact local corruption in tanzania. The Review of International Organizations, 12(2):227253.

Djankov, S., Montalvo, J. G., and Reynal-Querol, M. (2009). Aid with multiple personalities. Journal of Comparative Economics, 37(2):217 - 229.

Doucouliagos, H. and Paldam, M. (2009). The aid effectiveness literature: The sad results of 40 years of research. Journal of Economic Surveys, 23(3):433-461.

Dreher, A. and Kilby, C. (2010). The impact of aid on growth revisited: Do donor motives matter? Economics Letters, 107(3):338 - 340. 
Dreher, A., Klasen, S., Vreeland, J. R., and Werker, E. (2013a). The costs of favoritism: Is politically driven aid less effective? Economic Development and Cultural Change, 62(1):157-191.

Dreher, A., Minasyan, A., and Nunnenkamp, P. (2013b). Government ideology in donor and recipient countries: Does political proximity matter for the effectiveness of aid? Kiel Institute for the World Economy (IfW) Working paper.

Dreher, A., Nunnenkamp, P., and Thiele, R. (2011). Are new donors different? comparing the allocation of bilateral aid between nondac and dac donor countries. World Development, 39(11):1950 - 1968.

Easterly, W. and Birdsall, N. (2008). Reinventing foreign aid. Cambridge: MIT Press.

Easterly, W. and Pfutze, T. (2008). Where does the money go? best and worst practices in foreign aid. The Journal of Economic Perspectives, $22(2): 29-52$.

Easterly, W. and Williamson, C. R. (2011). Rhetoric versus reality: The best and worst of aid agency practices. World Development, 39(11):1930 -1949 .

Findley, M. G., Milner, H. V., and Nielson, D. L. (2017). The choice among aid donors: The effects of multilateral vs. bilateral aid on recipient behavioral support. The Review of International Organizations, 12(2):307-334.

Gehring, K., Michaelowa, K., Dreher, A., and Sparri, F. (2017). Aid fragmentation and effectiveness: What do we really know? World Development, 99:320 - 334.

Gulrajani, N. (2016). Bilateral versus multilateral aid channels: Strategic choices for donors. ODI Report.

Halonen-Akatwijuka, M. (2007). Coordination Failure in Foreign Aid. The B.E. Journal of Economic Analysis $\&$ Policy, 7(1):1-40.

Isaksson, A.-S. and Kotsadam, A. (2018). Chinese aid and local corruption. Journal of Public Economics, 159:146 - 159.

Jones, S. and Tarp, F. (2016). Does foreign aid harm political institutions? Journal of Development Economics, 118:266 - 281. 
Kellerman, M. (2018). The proliferation of multilateral development banks. The Review of International Organizations.

Knack, S. (2013). Aid and donor trust in recipient country systems. Journal of Development Economics, 101:316 - 329.

Knack, S. and Rahman, A. (2007a). Donor fragmentation and bureaucratic quality in aid recipients. Journal of Development Economics, 83(1):176 197.

Knack, S. and Rahman, A. (2007b). Donor fragmentation and bureaucratic quality in aid recipients. Journal of Development Economics, 83(1):176 197.

Knack, S. and Rahman, A. (2008). Donor fragmentation. In 'Reinventing Foreign Aid' (Cambridge, Editor W. Easterly).

Knack, S. and Smets, L. (2013). Aid tying and donor fragmentation. World Development, 44:63 - 76 .

Minasyan, A., Nunnenkamp, P., and Richert, K. (2017). Does aid effectiveness depend on the quality of donors? World Development, 100:16 30.

Morrissey, O., Clist, P., and Isopi, A. (2012). Selectivity on aid modality: determinants of budget support from multilateral donors. Review of International Organizations.

OECD (2008a). Report on the division of labor: Addressing global fragmentation and concentration. OECD_Development Co-operation Directorate Report.

OECD (2008b). Survey on monitoring the paris declaration: Making aid effective by 2010. OECD_Development Assistance Commitee.

Okada, K. and Samreth, S. (2012). The effect of foreign aid on corruption: A quantile regression approach. Economics Letters, 115(2):240 - 243.

Rajan, R. G. and Subramanian, A. (2008). Aid and growth: What does the cross-country evidence really show? Review of Economics and Statistics, 90(4):643-665.

Roodman, D. (2006a). Aid project proliferation and absortive capacity. Working paper, Center for Global Development. 
Roodman, D. (2006b). Competitive proliferation of aid projects: A model. Working paper, Center for Global Development.

Steel, I., Dom, R., Long, C., Monkam, N., and Carter, P. (2018). The taxation of foreign aid. ODI Briefing Note.

Svensson, J. (2003). Why conditional aid does not work and what can be done about it? Journal of Development Economics, 70(2):381 - 402.

Tingley, D. (2010). Donors and domestic politics: Political influences on foreign aid effort. The Quarterly Review of Economics and Finance, 50(1):40 -49 .

Walz, J. and Ramachandran, V. (2011). Brave new world. a literature review of emerging donors and the changing nature of foreign assistance. Working paper, Center for Global Development.

Williamson, C., Agha, A., Bjornstad, L., Twijukye, G., Mahwago, Y., and Kabelwa, G. (2008). Building blocks or stumbling blocks? the effectiveness of new approaches to aid delivery at the sector level. ODI Working paper. 